\title{
DESIGN AND SIMULATION OF A MEASURING DEVICE FOR A PHOTOVOLTAIC SYSTEM CONTROLLED BY PSOC5LP
}

\author{
JULIÁN R. CAMARGO L., ELVIS E. GAONA G \& OSCAR D. FLÓREZ C. \\ Engineering Faculty, Universidad Distrital Francisco José de Caldas, Bogotá, Colombia
}

\begin{abstract}
This document presents the design process, simulation with PSIM software and implementation of a conditioning system for the voltage signals of the different stages of generation, storage and conversion of a photovoltaic system controlled with a PSoC5LP, which allows the measurement of the power generated and consumed to later perform its energy management.
\end{abstract}

KEYWORDS: Photovoltaic System, PSIM, PSoC5LP, Sensors, Signal Conditioning

Received: Oct 08, 2020; Accepted: Oct 28, 2020; Published: Nov 12, 2020; Paper Id.: IJMPERDOCT202046

\section{INTRODUCTION}

When a system is required to supply electricity efficiently and to care for the environment, renewable energy generation systems are immediately thought of as a viable alternative [1]. Photovoltaic energy generation systems are currently being implemented in rural areas to power homes [2], [3], process automation systems in agriculture [4] or wireless systems [5] among others.

Particularly in the case of Colombia, the economy grew by $3.1 \%$ in 2015 , down from the average recorded between 2011 and 2014 (4.5\%). The demand for electrical energy in Colombia as of March 2016 reached 5567 $\mathrm{kWh}$ with a decrease of $0.6 \%$ over the previous year's figures. The growth rate of demand for electrical energy contracted, due primarily to the reduction in the level of activity in the energy mining sector derived from the fall in the price of raw materials [6], [7].

A typical photovoltaic system is composed of a bank of energy storage in batteries to be used with different loads, in situations of little sun or during the nights where it is possible to generate energy [8]-[10]. It is possible to have systems interconnected to the grid, which like other systems allow the batteries to be charged, the energy generated by these and by the solar panels is of the direct current (DC) type. At present, a large number of loads or electrical devices operate with AC at $120 \mathrm{Vrms}$, so it is necessary to implement voltage inverters that convert the energy generated by the DC type photovoltaic system, to the consumption energy of AC type [11]-[13].

In order to properly monitor the energy generated in these systems, the measurement of power generated and consumed is normally performed, which facilitates management [14]-[16]. This way, it can be used to feed the different devices and allows to guarantee quality in the process, allowing to establish failure conditions of the system, and statistics for consumption databases in the different places.

With the current development of microcontrollers and programmable devices, the measurement of the variables of the photovoltaic system is greatly facilitated [17], [18] since they simplify data processing through the 
use of internal analog-to-digital conversion modules, making it necessary to implement conditioning circuits that restrict the original working range of the system to the logical range allowed by these programmable devices. Also included in the same programmable device are systems that allow the storage (in Micro SD type memory or similar) or transmission of these data, for their later use in a control center for analysis, thus generating databases of the acquired variables.

For the development of the system presented in this document, the PSoC (Programmable System on Chip) of the 5LP family was used, which is a programmable system on chip developed by the North American company Cypress Semiconductor. The PSoc5LP has several analog and digital function modules, and also has a fully configurable architecture that makes it ideal for applications in embedded systems, based on a block programming structure for the development of modeling applications [19]-[20].

With a single PSoC5LP can design and implement, at very low cost, a complete system for the management of photovoltaic energy, in Figure 1 you can see this development, wherewith the internal modules of conversion from analog to digital PSoC has measured the variables that allow the calculation and monitoring of the input and output power of the system, in addition to a data transmission system.

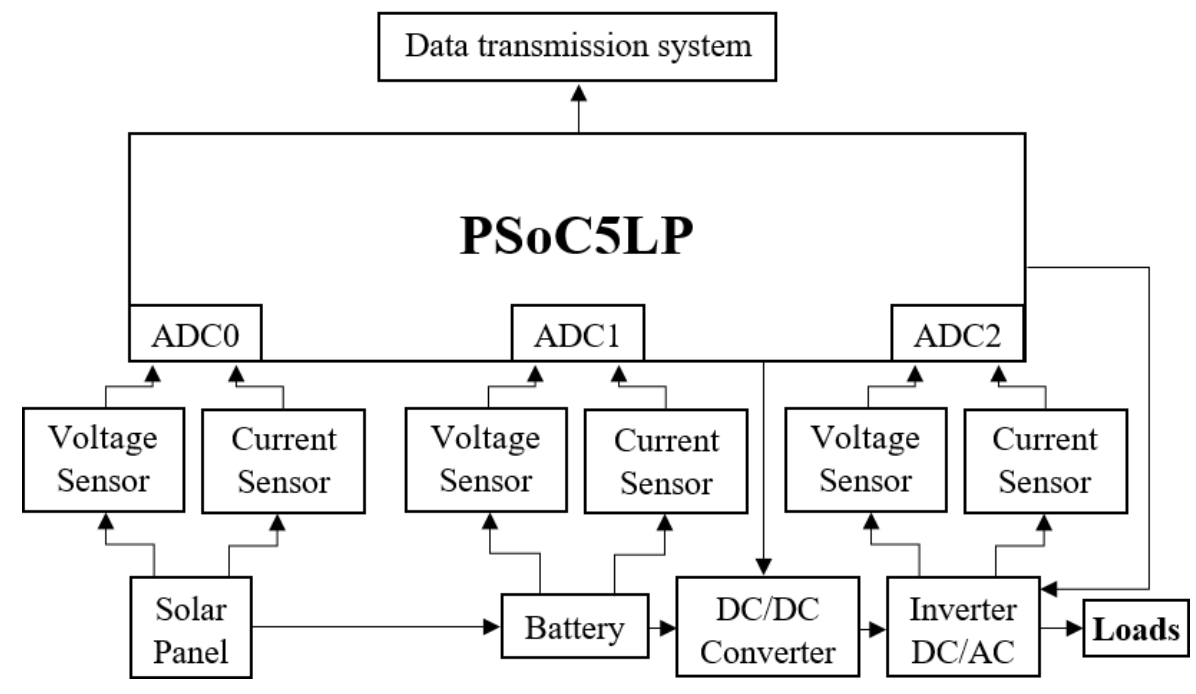

Figure 1: Diagram of a Photovoltaic Energy Management System with PSoC5LP

\section{METHODOLOGY}

The objective of this work is to simulate and implement the signal conditioning for three sensors, two in direct current (DC) and one in alternating current (AC), within a photovoltaic energy generation system, allowing constant monitoring of power generated and consumed by the system.

This process is performed by measuring the voltage variable in the different blocks of conversion of the generation system with the implementation of an embedded system, making use of the programmable device PSoC5LP, which works with voltage levels in a range of $0 \mathrm{v}$ to $5 \mathrm{v}$ [19], [20]. Each of the signal conditioning must meet the requirements of the energy conversion stage in which they will be implemented, taking into account the different conditions of each stage as in its nature and amplitude.

\subsection{Mathematical Modeling of Solar Panel Voltage Signal Conditioner}

The solar panel used for the development of the project is a 240W reference Poly Solar Panel, model SL240CE-30P [21] 
which has the characteristics shown in Table 1.

Table 1: Main characteristics of the solar panel [19]

\begin{tabular}{|l|l|l|}
\hline Parameter & Symbol & Value \\
\hline Peak Power & $\mathrm{P}_{\text {máx }}$ & $240 \mathrm{~W}$ \\
\hline Maximum Power Current & $\mathrm{I}_{\mathrm{mp}}$ & $7.81 \mathrm{~A}$ \\
\hline Maximum Power Voltage & $\mathrm{V}_{\mathrm{mp}}$ & $30.72 \mathrm{~V}$ \\
\hline Short Circuit Current & $\mathrm{I}_{\mathrm{sc}}$ & $8.36 \mathrm{~A}$ \\
\hline Open Circuit Voltage & $\mathrm{V}_{\mathrm{oc}}$ & $36.6 \mathrm{~V}$ \\
\hline
\end{tabular}

Figure 2 shows the characteristic curve required for the conditioning of the voltage signal coming from the solar panels of the generation system.

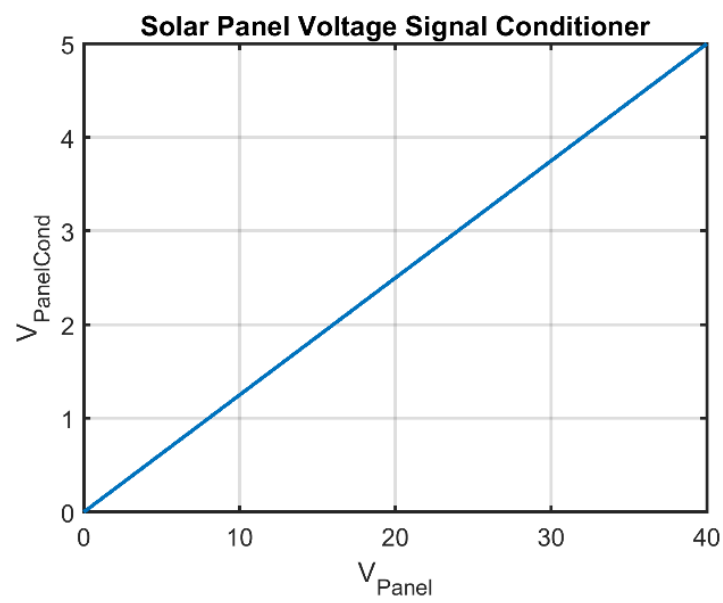

Figure 2: Solar panel voltage signal conditioning

The mathematical model that linearly relates the above variables, i.e. input variable or independent (Solar Panel Voltage Signal $\mathrm{V}_{\text {Panel }}$ ) and output variable or dependent (Solar Panel Voltage Conditioned Signal $\mathrm{V}_{\text {PanelCond }}$ ) is defined in (1).

$$
\frac{V_{\text {PanelCond }}}{v}=\frac{1}{8} * \frac{V_{\text {Panel }}}{v}
$$

\subsection{Mathematical Modeling of Battery Voltage Signal Conditioner}

The signal conditioning requirements for battery voltage are shown in Figure 3.

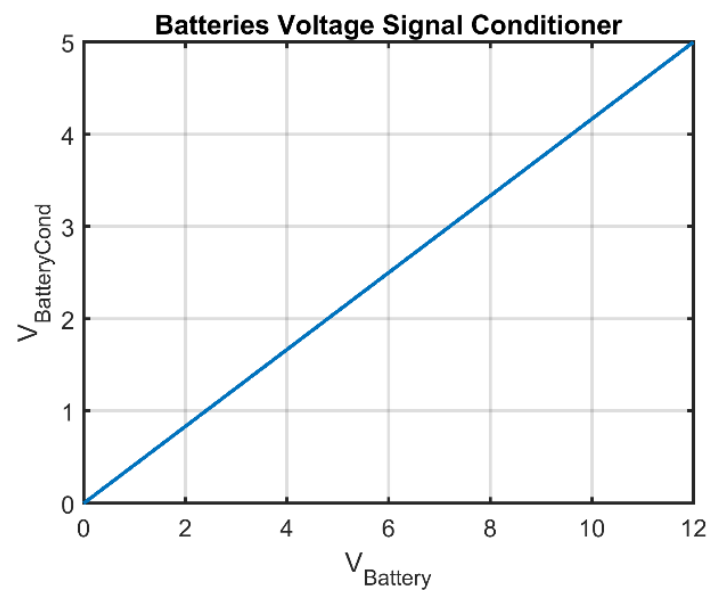

Figure 3: Batteries voltage signal conditioning 
The mathematical model that relates linearly the variables for the conditioning of the battery voltage signal that will allow knowing the state of charge of this device is defined by the input variable or independent Battery Voltage Signal $\left(\mathrm{V}_{\text {Battery }}\right)$ and output variable or dependent Conditioned Battery Voltage Signal $\left(\mathrm{V}_{\text {BatteryCond }}\right)$ is defined in (2).

$$
\frac{V_{\text {BatteryCond }}}{v}=\frac{1}{3} * \frac{V_{\text {Battery }}}{v}
$$

\subsection{Mathematical Modeling of Inverter Voltage Signal Conditioner}

The voltage signal of the power voltage inverter $600 \mathrm{~W}$, is an alternating current signal with frequency $60 \mathrm{~Hz}$ and Amplitude $170 \mathrm{~V}$, to perform the conditioning initially this signal is used a transformer with a ratio 10:1 that decreases the working range from $-170 \mathrm{v}$ to $170 \mathrm{v}$, to a working range of $-17 \mathrm{v}$ to $17 \mathrm{v}$, also considering the level of the transient with a maximum value of $20 \mathrm{~V}$, it extends the range from $-20 \mathrm{v}$ to $20 \mathrm{v}$, which should be equivalent to the working range of the programmable device PSoC5LP, in Figure 4 we can see the necessary response for the voltage signal conditioner of the inverter attenuated with the transformer.

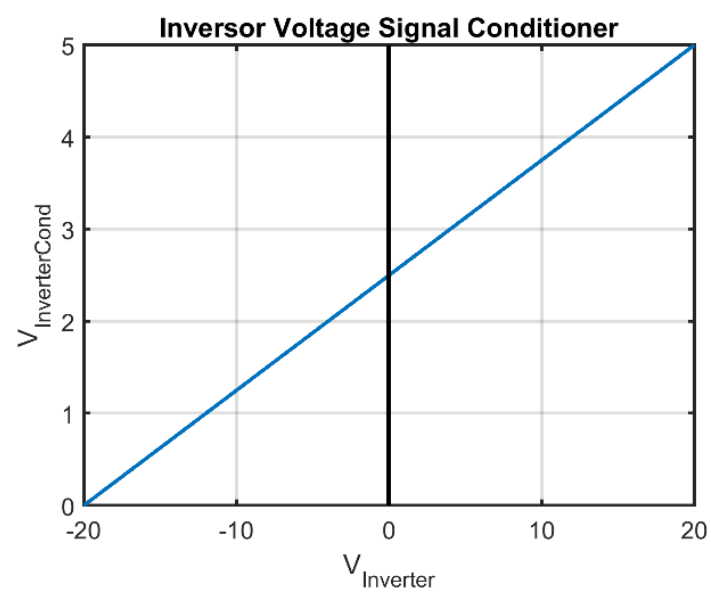

Figure 4: Inverter voltage signal conditioner

The mathematical model that defines the voltage conditioner for the signal from the voltage transformer connected to the inverter is defined in (3).

$$
\frac{V_{\text {InverterCond }}}{v}=\frac{1}{8} * \frac{V_{\text {Inverter }}}{v}+2.5
$$

\section{DESIGN OF SIGNALS CONDITIONER}

\subsection{Solar Panel Voltage Signal Conditioner}

To obtain a signal conditioning through a linear relation between the input signal (Solar Panel Voltage Signal) in a range of 0V - 40V and the output signal (Solar Panel Voltage Conditioned Signal) in a range of 0V - 5V a voltage divider was designed considering the maximum input current to the PSoC5LP pins. The circuit diagram used for the design is shown in Figure 5.

Analyzing the conditioning circuit, represented by a voltage divider, the ratio (4) was obtained. 


$$
\frac{V_{\text {RPanelCond }}}{v}=\frac{V_{\text {SolarPanel }} * R_{\text {PanelCond }}}{R_{\text {PanelCond }}+R_{S P}}
$$

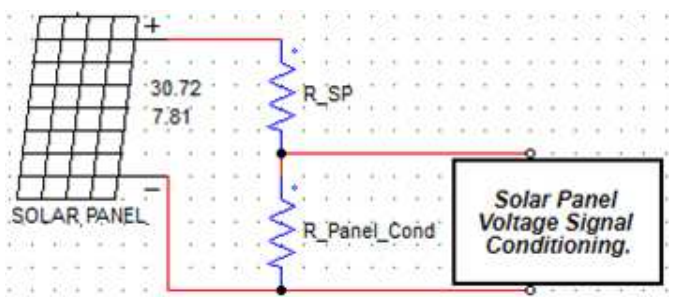

Figure 5: Conditioner for the solar panel voltage signal

As the maximum input current of the programmable device is $I_{\text {máxPsoC }}=6 \mathrm{~mA}$, the equivalent resistive value that the branch must have in parallel to the voltage source is calculated in this case the solar panel with (5).

$$
R_{\text {PanelCond }}+R_{S P}=\frac{40 v}{6 m A}=6.7 k \Omega
$$

By replacing the equivalent voltage and resistance values for that total current on the branch, the value shown in (7) is obtained.

$$
\begin{aligned}
& 5 v=\frac{40 v * R_{\text {PanelCond }}}{6.7 k \Omega} \\
& R_{\text {PanelCond }}=837,5 \Omega
\end{aligned}
$$

Finally, with commercial values of resistances, the $\mathrm{R}_{\text {PanelCond }}$ values are obtained. The RSP resistor is built to be implemented by 2 resistors $\mathrm{R}_{\mathrm{SP} 1}$ and $\mathrm{R}_{\mathrm{SP} 2}$, their values together with $\mathrm{R}_{\text {PanelCond, }}$ are shown in (8).

$$
\begin{aligned}
& R_{\text {PanelCond }}=820 \Omega \\
& R_{S P 1}=2 \mathrm{k} \Omega \\
& R_{S P 2}=3.9 \mathrm{k} \Omega
\end{aligned}
$$

\subsection{Batteries Voltage Signal Conditioner}

A voltage divider was designed that provides a linear relationship between the input signal (Lithium-Ion Battery Voltage Signal) working in the range of $0 \mathrm{~V}$ to $15 \mathrm{~V}$ depending on the state of charge, and an output signal (Conditioned Battery Voltage Signal) working in the range of the PSoC5LP from $0 \mathrm{~V}$ to $5 \mathrm{~V}$, considering the maximum current at the input pins. The circuit diagram used for the design is shown in Figure 6.

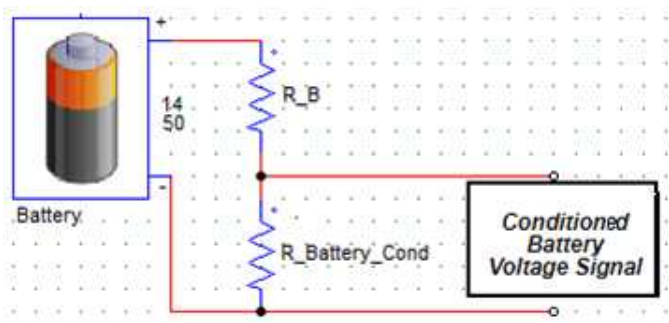

Figure 6: Conditioner of panel solar voltage signal

To calculate the voltage on $\mathrm{R}_{\text {BatteryCond, }}$ use (9). 


$$
V_{\text {RBatteryCond }}=\frac{V_{\text {BatteryCond }} * R_{\text {BatteryCond }}}{R_{\text {BatteryCond }}+R_{B}}
$$

Replacing the voltage values of the source voltage, in this case, the Li-Ion battery in its maximum state of charge and the maximum value of the working range of the programmable device results in (10) and (11).

$$
\begin{aligned}
& 5 v=\frac{15 v^{*} R_{\text {BatteryCond }}}{R_{\text {BatteryCond }}+R_{B}} \\
& 5^{*} R_{B}+5^{*} R_{\text {BatteryCond }}=15^{*} R_{\text {BatteryCond }}
\end{aligned}
$$

By finally clearing it is obtained a relation between the two resistance values of the branch in parallel to the battery as can be seen in (12).

$$
R_{\text {BatteryCond }}=\frac{1}{2}+R_{B}
$$

Finally, with commercial resistance values, the branch resistors are selected that comply with the ratio of (12) and also with the current limitation of the programmable device $\left(\mathrm{I}_{\operatorname{maxPSoC}}=6 \mathrm{~mA}\right)$.

$$
\begin{aligned}
& R_{\text {BatteryCond }}=15 \mathrm{k} \Omega \\
& R_{B}=30 \mathrm{k} \Omega
\end{aligned}
$$

\subsection{Inverter Voltage Signal Conditioner}

The signal is output from the inverter circuit, it is an alternating signal with $\mathrm{f}=60 \mathrm{~Hz}$, Vrms $=120 \mathrm{VAC}$ therefore $\mathrm{V}_{\text {maxinverter }}=170 \mathrm{~V}$.

To carry out conditioning that guarantees the protection of the programmable device, an electric transformer was selected, taking advantage of its electric isolation characteristic due to its construction, allowing it to isolate the power part of the measuring system. The transformer has a 10:1 ratio, so the output signal has characteristics of $\mathrm{f}=60 \mathrm{~Hz}, \mathrm{Vrms}=12 \mathrm{~V}$.

The conditioning implemented for the measurement of the transformer signal consists of an arrangement of 3 resistors, with an additional voltage source, which provides a DC level and again to the input signal, to work in the range of the programmable device $(0 \mathrm{v}-5 \mathrm{v})$. The implemented circuit is shown in Figure 7.

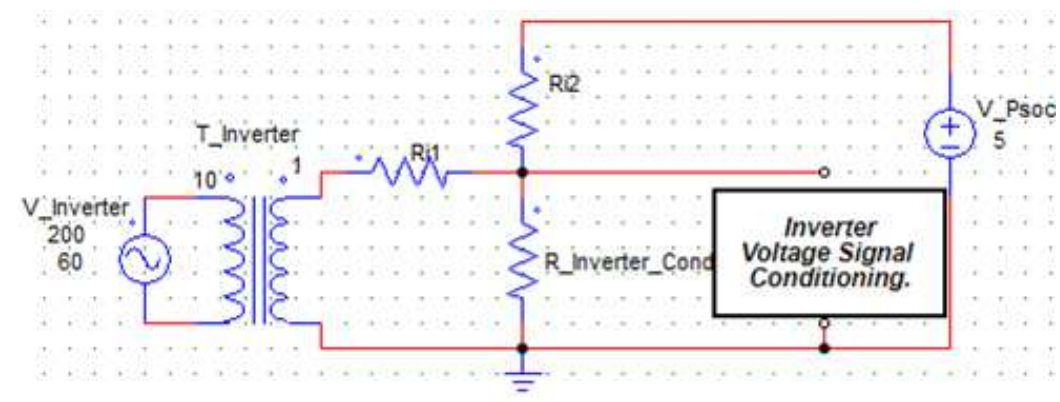

Figure 7: Conditioner of the inverter voltage signal

The analysis of this conditioning depends on the model of the conditioner of (3), below are the equations for the calculation of each of the resistances of the branch that are dependent on $m$ (Slope of the model or gain for conditioned 
signal), $b$ (Cut off the model with $\mathrm{Y}$-axis), and $\mathrm{V}_{\mathrm{CC}}$ of the source of the programmable device $\left(\mathrm{V}_{\mathrm{CC}}=5 \mathrm{~V}\right)$. A value is selected for the $\mathrm{R}_{\text {InverterCond }}$ resistor that meets the maximum input current requirement at the PSoC5LP pins.

$$
\begin{aligned}
& R_{i 2}=m *\left(\left(\frac{V c c-b}{b}\right) *\left(\frac{1-m}{m}\right)-1\right) * R_{\text {InverterCond }} \\
& R_{I 1}=\frac{R_{\text {InverterCond }}}{\left(\frac{m}{1-m}\right) *\left(1+\left(\frac{1}{m^{*} *\left(\left(\frac{V c c \_b}{b}\right) *\left(\frac{1 \_m}{m}\right)-1\right)}\right)\right)}
\end{aligned}
$$

$m=0.13$

$b=2.5$

$V c c=5 v$

$R_{\text {InverterCond }}=10 \mathrm{k} \Omega$

By replacing the previous values in (14) and (15) the following values are obtained for each of the branch resistors

$$
\begin{aligned}
& R_{i 2}=15 \mathrm{k} \Omega \| 15 \mathrm{k} \Omega \\
& R_{i 1}=30 \mathrm{k} \Omega
\end{aligned}
$$

\section{SIMULATION}

With the design of the resistive conditioning for the voltage sensors implemented in each one of the energy sources (Battery and Solar Panel) and the inverter (Output Current), the simulation was done with the PSIM11.1.3 computer tool, with student license for the Universidad Distrital Francisco José de Caldas. In all cases of simulation for direct current conditioning, a parallel load was simulated to the different voltage sources to be measured and to the resistive conditioning circuit, to simulate current levels that the system has at that point and also to validate that the maximum current circulating through the conditioning circuit for measurement is lower than the nominal current that the PSoC5LP is capable of supporting.

\subsection{Solar Panel Voltage Signal}

The voltage and current conditions that are simulated at this point in the system are 40v and $4 \mathrm{~A}$ so the load that was used was from $10 \Omega$. Figure 8 shows the circuit diagram with the values of the resistances and the voltage value of the panel, also the voltmeters that were located in both the input and output of the coupling are observed. 


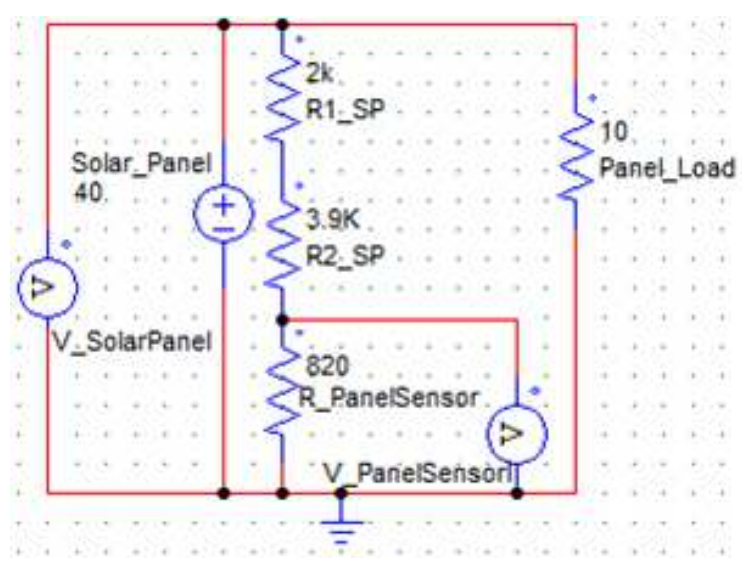

Figure 8: Diagram for simulation of voltage panel conditioner

The signals captured by the voltmeters throughout $0.25 \mathrm{~s}$ are shown in Figure 9, where at an input value of $40 \mathrm{v}$ the resistive conditioner attenuates the signal to a value of $4.8 \mathrm{v}$ meeting the requirements set out above.

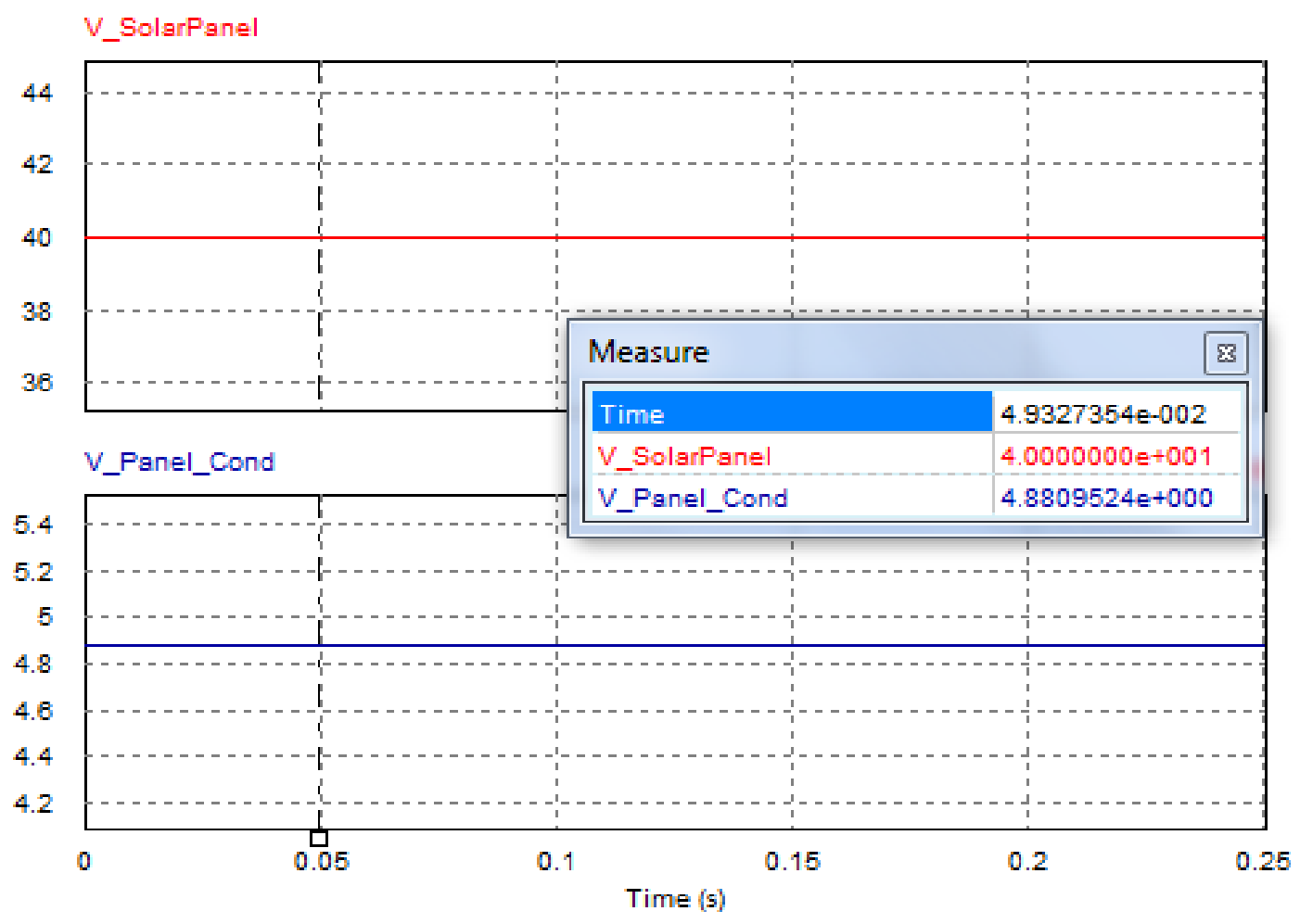

Figure 9: Simulation of conditioning for panel solar voltage signal

\subsection{Batteries Voltage Signal}

To measure the voltage in the batteries, the signal coupling diagram shown in Figure 10 was simulated, where it can be seen that the circuit has a voltage value equal to $15 \mathrm{v}$ and a current of $6 \mathrm{~A}$; despite the high value of the current in the circuit, it was verified that the current entering the PSoC5LP was not greater than $6 \mathrm{~mA}$. 


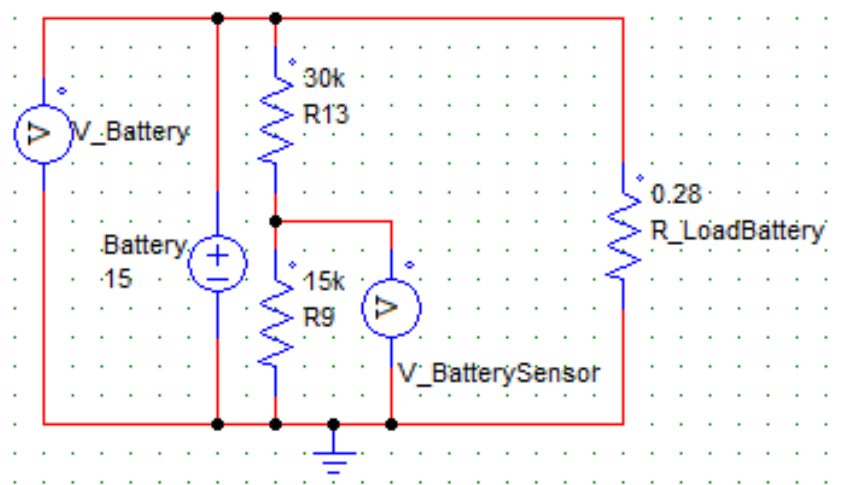

Figure 10: Diagram for simulation of voltage panel conditioner

The results of the voltage values at the input and output of the circuit are shown in Figure 11 which were $15 \mathrm{v}$ and $5 \mathrm{v}$ respectively, making it clear that the conditioning is working correctly.

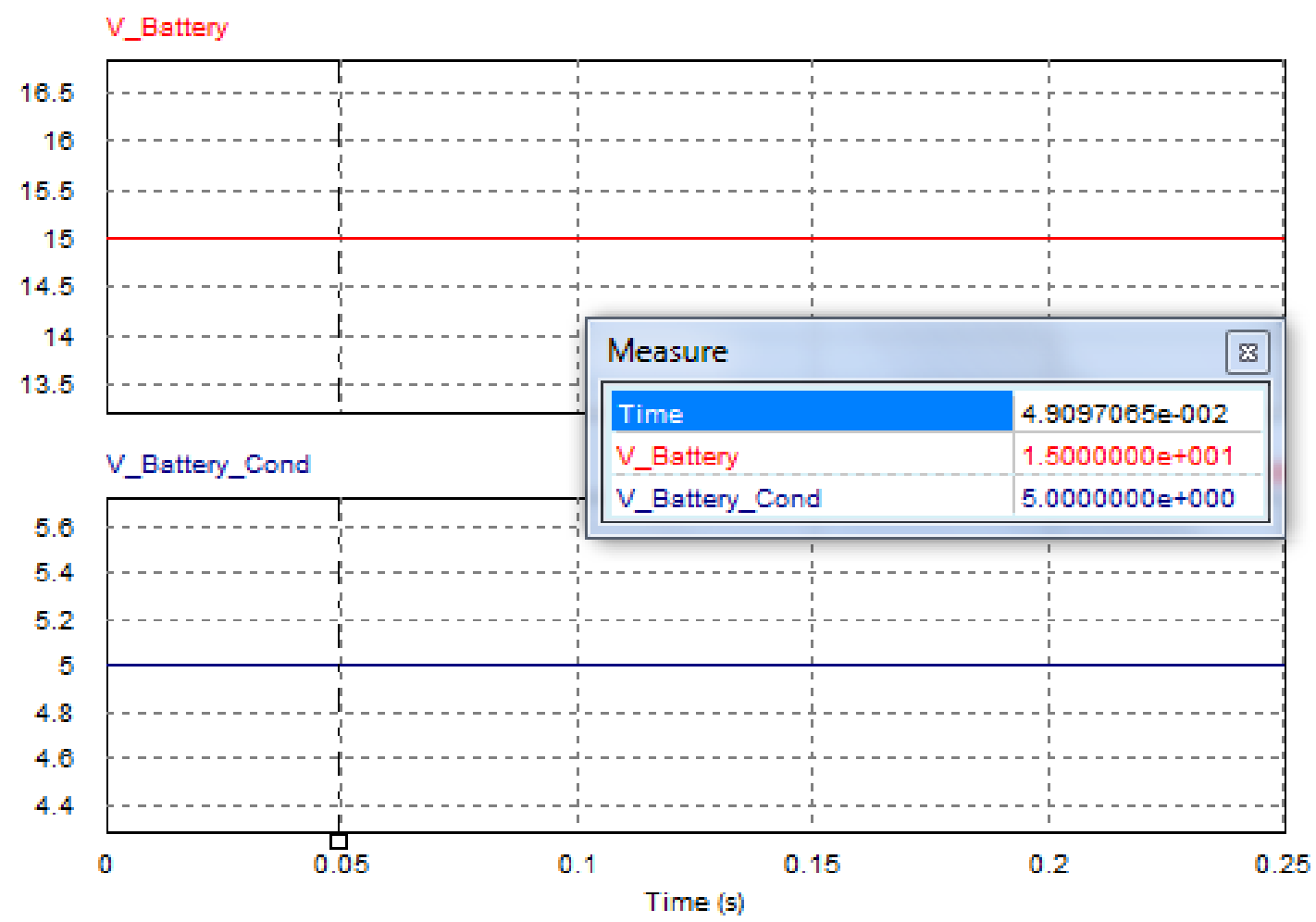

Figure 11: Simulation of conditioning for panel solar voltage signal

\subsection{Inverter Voltage Signal}

As it is a voltage coupling for an AC signal, this circuit diagram is different from the previous ones because it has a DC voltage source as shown in Figure 12, this to achieve attenuation and increase the average value of the input signal so that the programmable system can recognize the input signal coming from the inverter. 


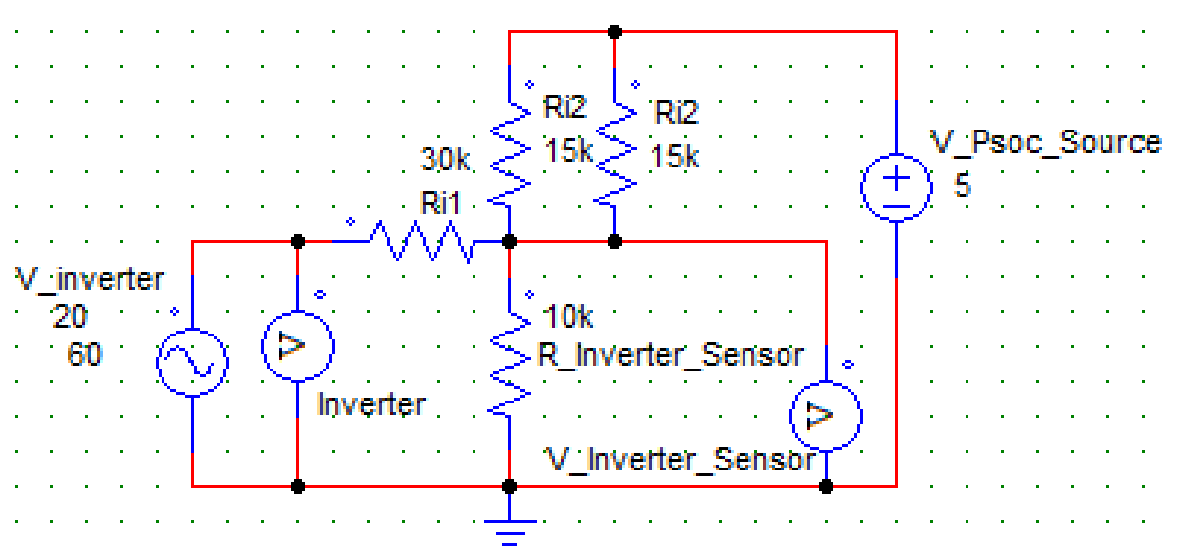

Figure 12: Diagram for simulation of voltage inverter conditioner

The simulation results shown in Figure 13 reveal that the coupling manages to condition a sine signal at the input whose peak-to-peak value is $40 \mathrm{v}$ (this means that the signal oscillates within a range of $-20 \mathrm{v}$ to $20 \mathrm{v}$ ) and average value equal to zero, to an output signal with an average value of $2.5 \mathrm{v}$ and a range of oscillation between $0 \mathrm{v}$ and $5 \mathrm{v}$; satisfying the system requirements.

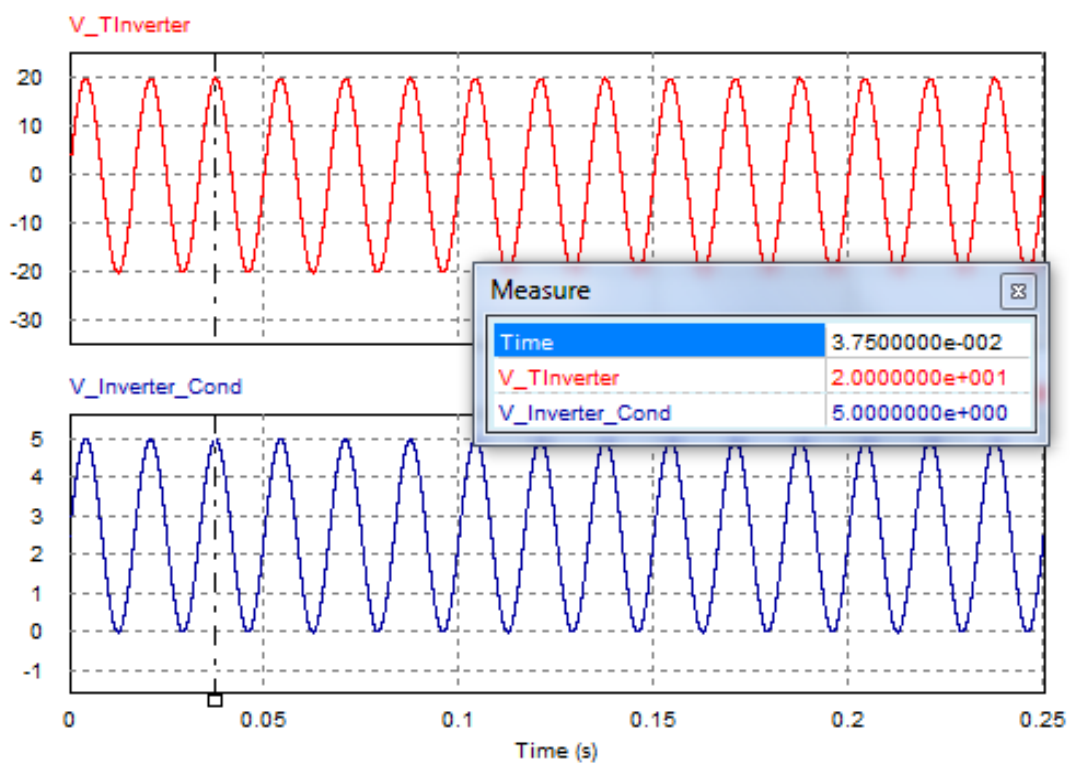

Figure 13: Simulation of conditioning for panel solar voltage signal

\section{RESULTS}

With the help of the design and simulation processes mentioned above, the results of these resistive conditioners were implemented and verified.

\subsection{Solar Panel Voltage Signal}

Figure 14 shows two DC voltage signals which belong to the input signal (Blue) and the output signal (Red) of the coupling system; furthermore, it can be seen that the maximum value of the blue signal is equal to $36.4 \mathrm{v}$ while that of the red signal is $4.48 \mathrm{v}$. 


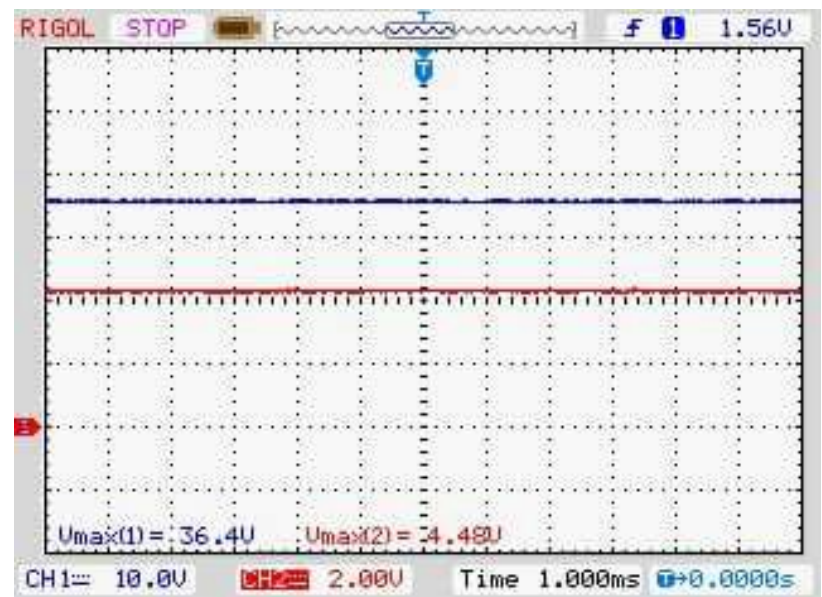

Figure 14: Results obtained from the conditioning for solar panels

With these results it can be stated that the conditioning fulfilled its main function, which was to decrease the output voltage so that it was within the working range of the PSoC5LP, however, when verifying the values with the help of equation 1 the output value with an input of $36.4 \mathrm{v}$ should have been $4.55 \mathrm{v}$ and not $4.48 \mathrm{v}$, thus generating an error percentage of approximately $1.54 \%$.

\subsection{Batteries Voltage Signal}

For this voltage conditioner present in the system's batteries with an input signal (blue) of 12.1v, an output signal (red) of $4.08 \mathrm{v}$ was obtained, as shown in Figure 15.

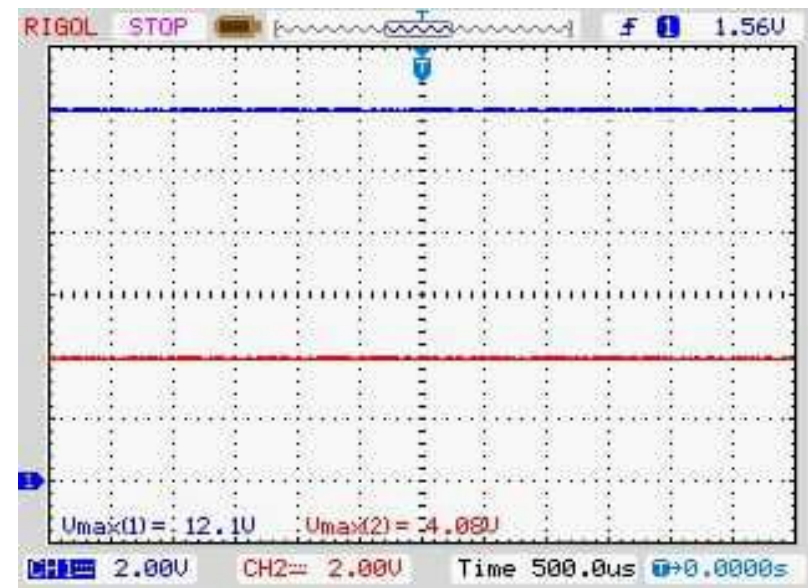

Figure 15: Results obtained from the conditioning in the system's batteries

As in the previous case, this result has a percentage of error of approximately $1.16 \%$, obtained by comparing the result obtained in the image with the result obtained in (2). Despite this error found, it should be clarified that the voltage attenuation ratio is very close to the real one and that the conditioner fulfilled its main objective.

\subsection{Inverter Voltage Signal}

The results obtained for the voltage conditioner located in the system's inverter are shown in Figure 16. As in the previous cases, the input and output signals of the system will be represented with blue color and red color respectively; for this particular case it was started with a sinusoidal signal of peak value equal to $180.6 \mathrm{v}$ with a frequency equal to $60 \mathrm{~Hz}$, 
however, after being attenuated with a 1:10 ratio transformer, a sinusoidal signal of 16.6v peak and equal frequency was obtained, so it can be inferred that the transformer has an efficiency of approximately $93 \%$.

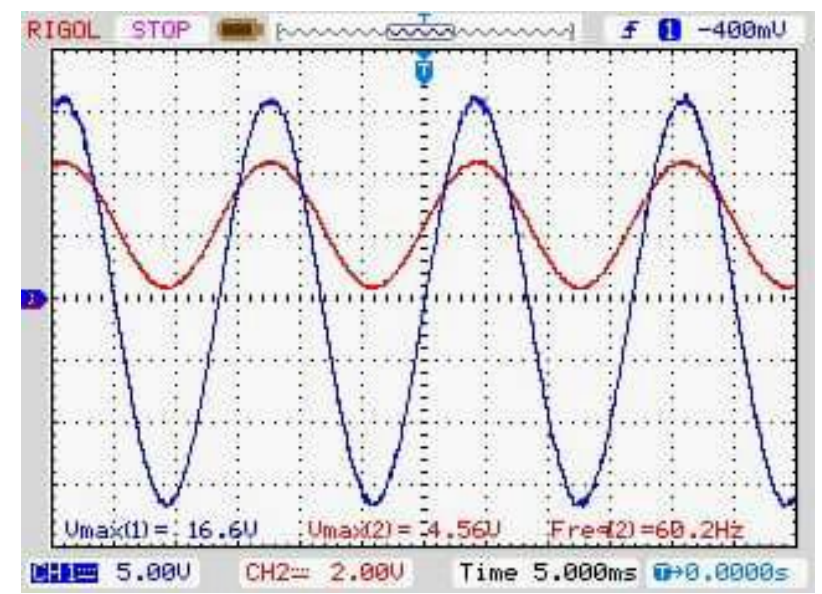

Figure 16: Results obtained from the conditioning in the system's inverter

The figure shows a sinusoidal output signal with a peak value equal to $4.56 \mathrm{v}$, a frequency of $60.2 \mathrm{~Hz}$ and an error percentage of approximately $0.33 \%$, obtained from (3), however, it should also be noted that this signal is in phase with the input signal, also it is attenuated and finally, its average value is very close to $2.5 \mathrm{v}$, so it is a signal recognizable by the PSoC5LP and the main objective of the signal conditioner was met satisfactorily.

\section{CONCLUSIONS}

As can be seen in all cases, the objective for each of the signal conditioners was met, which was to obtain an output signal with the same characteristics as the input signal and that complied with the mathematical model stipulated with appropriate values so that the PSoC5LP programmable system would recognize them without any problem; However, in the middle of this process, some errors were generated whose percentages are very low and can be negligible, whose generation was due to the tolerance of the resistors and measuring instruments used to obtain the images shown, in addition to the transformer used only in the measurement of the system inverter conditioner.

The signal conditioning process is the first step in creating automation processes within this system; therefore, obtaining these small errors lead to correction with the help of the PSoC5LP to obtain efficient and fast results when putting the system into operation.

The resistive conditioning is a fast alternative because its mathematical model is linear and the materials to be used are of an easy obtaining with a low cost, nevertheless, it does not mean that it is the most efficient solution, only that for this particular case it was adapted to the basic needs of the system.

\section{ACKNOWLEDGMENTS}

The authors would like to thank the Universidad Distrital Francisco José de Caldas and the LASER research group that supported the development and testing of the project. 


\section{REFERENCES}

1. Rule, T. A. (2014). Solar, Wind and Land-Conflicts in renewable energy development, 1st ed., New York: Routledge, 2014.

2. Narváez, J. R., Aguas, F. de J. \& Oviedo, J. M. (2012). Diseño y dimensionamiento de plantas solares autónomas para viviendas típicas de la zona rural del departamento de Córdoba. Elementos. 2(2):67-81.

3. Gaona, E. E., Trujillo, C. L. \&Guacaneme, J. A. (2015). Rural microgrids and its potential application in Colombia. Renewable and Sustainable Energy Review. 51:125-137.

4. Rodríguez, H. (2009). Desarrollo de la energía solar en Colombia y sus perspectivas. Revista de Ingeniería. 28:83-89.

5. Mazurek, G. (2013). Performance Study of Solar Power Source for Wireless Systems.International Journal of Electronics and Telecommunications. 59(3):271-276.

6. AHN - Agencia Nacional de Hidrocarburos - Colombia. (2015). Estadísticas de Producción. Retrievedfrom: http://www.anh.gov.co/Operaciones-Regalias-y-Participaciones/Sistema-Integrado-de-Operaciones/Paginas/Estadisticas-deProduccion.aspx

7. Bueno, M., Rodríguez, L. C. \&Rodríguez, P. J. (2016). Análisis de costos de la generación de energía eléctrica mediante fuentes renovables en el sistema eléctrico colombiano. Ingeniería y Desarrollo. 34(2):397-419.

8. Ahmad, M. (2017). Operation and Control of Renewable Energy System, 1st ed., Wiley, 2017.

9. Al-Najideen, M. I. \&Alrwashdeh, S. S. (2017). Design of a solar photovoltaic system to cover the electricity demand for the faculty of Engineering- Mu'tah University in Jordan. Resource-Efficient Technologies. 3(4):440-445.

10. van Sark, W. (2019). Photovoltaic System Design and Performance. Energies. 12(10):1826-1832.

11. Kumar, S., Verma, A. K., Hussain, I., Singh, B. \&Jain, C. (2017). Better Control for a Solar Energy System: Using Improved Enhanced Phase-Locked Loop-Based Control Under Variable Solar Intensity. IEEE Industry Applications Magazine. 23(2):24-36.

12. Li, P., François, B. Degobert P. \&Robyns, B. (2007). Power Control Strategy of a Photovoltaic Power Plant for Microgrid Applications.In ISES Solar World Congress 2007: Solar Energy and Human Settlement, Berlin, 2007.

13. Hassaine, L. \&Bengourina, M. R. (2019). Control technique for single phase inverter photovoltaic system connected to the grid. In Tmrees, EURACA, Grecia, 2019.

14. Cheng, Z., Li, Z., Liang, J., Si, J., Dong, L. \& Gao, J. (2018). Energy management strategy for integrating photovoltaic energy in AC microgrid. Journal of Renewable and Sustainable Energy. 10(6).

15. Böttiger, M., Paulitschke, M. \&Bocklisch, T. (2016). Innovative Reactive Energy Management for a Photovoltaic Battery System. In 10th International Renewable Energy Storage Conference, Düsseldorf, 2016.

16. Kulkarni, A. R., Mujumdar, K. N., Patil, V. R., Mahale, N. S. \&Sindkar, M. P. (2020). Performance Enhancement of Solar Photovoltaic Panel Using Automated Solar Panel Cleaner. International Journal of Mechanical and Production Engineering Research and Development (IJMPERD). 10(3):12139-12148.

17. Islam, M. M., Rana, M. M., Mitul, A. F., Alamkhan, M. M., Talukder, A., Reja, M. I., Sarker, N., Hoque, M. N. \&Hazari, N. A. (2012). Microcontroller based power inverter for grid connected PV system. In 2012 International Conference on Green and Ubiquitous Technology, Bandung, 2012. 
18. Ali Baig, M. A. \&Saxena, A. (2018). Maximization of Photovoltaic Energy Generation by Time and Location Based Sun Tracking System. International Journal of Mechanical and Production Engineering Research and Development (IJMPERD). 8(4):437-444.

19. Camargo, J. \&Perdomo, C. (2016). Introducción al PSoC5LP: Teoría y aplicaciones prácticas, Ind ed., Bogotá: Ed. Universidad Distrital, 2016.

20. Camargo, J., Perdomo, C. \&Bermúdez, B. (2019). Proyectos prácticos con PSoC5LP, Ind ed., Bogotá: Ediciones de la U, 2019.

21. Made-in-China. (2019). Poly módulo solar 240W/31V. Retrieved from: https:/les.made-inchina.com/co_nbkxsolar/product_Poly-Solar-Module-240w-31v_heeyosisg.html 